\title{
APROVECHAMIENTO TRADICIONAL DE LAS AGUAS DE AVENIDA Y TRANSFORMACIONES DE LOS SISTEMAS FLUVIALES DEL SURESTE DE LA PENÍNSULA IBÉRICA: LA RAMBLA DE ABANILLA-BENFERRI
}

\begin{abstract}
RESUMEN
El aprovechamiento tradicional de las aguas de avenida, mediante presas de derivación y complejas redes de boqueras, generó un milenario sistema de organización hidrogeomorfológica en las cuencas vertientes del sureste de la Península Ibérica. Tal fue su implantación e importancia territorial que, durante siglos, en barrancos y ramblas se desarrolló una dinámica ecoantrópica en la que las avenidas fluviales se convirtieron en un valioso recurso para la agricultura, al tiempo que se redujo su peligrosidad. El rápido abandono de estos sistemas de laminación durante el s. xx, junto con la alteración de los cursos fluviales y los intensos cambios de usos del suelo, ha incrementado la peligrosidad de estas ramblas. El presente artículo aborda el estudio del último tramo de la rambla de Abanilla-Benferri (provincia de Alicante), como ejemplo paradigmático de estos procesos territoriales, aportando una primera
\end{abstract}

a Grupo de Investigación Medio, Sociedad y Paisaje (MedsPai). Dpto. de Análisis Geográfico Regional y Geografía Física, Instituto Interuniversitario de Geografía, Universidad de Alicante. Carretera San Vicente del Raspeig, s/n. 03690 San Vicente del Raspeig - Alicante. ja.marco@ua.es. http://orcid.org/0000-0003-3431-0499.

b Grupo de Investigación Medio, Sociedad y Paisaje (MedsPai). Dpto. de Análisis Geográfico Regional y Geografía Física, Instituto Interuniversitario de Geografía, Universidad de Alicante. Carretera San Vicente del Raspeig, s/n. 03690 San Vicente del Raspeig - Alicante. pablo.gimenez@ua.es. http://orcid.org/0000-0002-1171-715X.

c Grupo de Investigación Medio, Sociedad y Paisaje (MedsPai). Dpto. de Análisis Geográfico Regional y Geografía Física, Instituto Interuniversitario de Geografía, Universidad de Alicante. Carretera San Vicente del Raspeig, s/n. 03690 San Vicente del Raspeig - Alicante. a.prieto@ua.es. http://orcid.org/0000-0002-6086-6290.

Fecha de recepción: 12-07-2021. Fecha de aceptación: 14-09-2021. 
interpretación histórico-geomorfológica sobre su funcionamiento en el pasado y las consecuencias del abandono del sistema de riego tradicional.

Palabras clave: rambla de Abanilla-Benferri; cartografía histórica; riego de turbias; riada súbita.

\title{
TRADITIONAL USE OF FLOODWATERS AND TRANSFORMATIONS OF THE RIVER SYSTEMS OF THE SOUTHEAST OF THE IBERIAN PENINSULA: THE RAMBLA DE ABANILLA-BENFERRI
}

\begin{abstract}
In the southeast of the Iberian Peninsula a millennial hydrogeomorphological organization system was developed in river basins, based on the use of flood waters. This traditional use was carried out through complex networks of derivation dams and "boqueras" (irrigation ditches). Its implantation and territorial importance was so great that an eco-anthropic dynamic developed over centuries. Here the fluvial avenues became a valuable resource for agriculture, reducing its danger. The rapid abandonment of these rolling systems during the 20th century, together with the alteration of the river courses and the intense changes in land use, has increased the danger of these ravines. This article studies the last section of the rambla de Abanilla-Benferri (Alicante province), as a paradigmatic example of these described territorial processes. A first historical-geomorphological interpretation of the functioning of the river in the past and the consequences of the abandonment of the traditional irrigation system is presented.
\end{abstract}

KeYwords: rambla de Abanilla-Benferri; historical cartography; irrigation with muddy water; flash flood.

\section{INTRODUCCIÓN}

El sistema de riego de turbias, organizado para desviar, mediante presas y boqueras, el manto pluvial de las crecidas de ramblas y cauces intermitentes, ha sido considerado como el más relevante sistema de regulación y ordenación hidrogeomorfológica de las cuencas vertientes del sureste de la Península Ibérica (Morales, 1969). Sobre su importancia, Morales et al. (1989) destacan, además, que suponen una "considerable merma de caudales que, retenidos por los aterrazamientos y desviados por las boqueras, disminuyen de forma notoria las ondas de crecida, las cuales, a su vez, experimentan una laminación que contribuye a minorar los negativos efectos de fuertes y rápidas avenidas". A pesar de la notable producción científica realizada por geógrafos españoles sobre esta materia (Morales \& Box, 1986; Mondéjar, 2009; Hernández \& Morales, 2013; Marco \& Box, 2019), faltan todavía estudios que profundicen en aspectos tan relevantes como la propia reconstrucción de las superficies beneficiadas, el alcance de los débitos sustraídos del caudal de los ríos o el papel que el abandono de estos sistemas ha jugado en la génesis de las riadas más recientes (Marco et al., 2020). Sin olvidar las posibilidades que, en el marco de las soluciones basadas en la naturaleza $(\mathrm{SbN})$, podría ofrecer este conocimiento 
tradicional a la hora de incrementar la resiliencia de las sociedades amenazadas por el riesgo de inundación (FEMP, 2019).

De esta forma, se podrían enumerar una serie de objetivos generales que, aplicados a gran parte de los sistemas fluviales históricamente controlados por el riego de turbias, cimentarían una hipótesis general de trabajo. Dicha hipótesis está dirigida a entender la transición de sistemas sometidos a una dinámica ecoantrópica a otra dinámica más caótica, dominada por el abandono de los aprovechamientos pluriseculares y, claramente, más peligrosa para el ser humano. Para ello, sería necesario atender a los siguientes pasos:

- Obtener una representación de las características del sistema fluvial a partir de la documentación histórica, con especial referencia a la cartografía histórica.

- Constatar la existencia de los sistemas de derivación y conducción de las aguas, presas y boqueras, así como los espacios, fundamentalmente agrícolas, beneficiados con las aguas de avenida. Se trata, pues, de abordar el inventario de los diferentes elementos del sistema.

- Reconstruir el funcionamiento del sistema fluvial con estas circunstancias de dinámica ecoantrópica.

- Tratar de determinar hasta qué momento se han mantenido en funcionamiento los sistemas de derivación. En consonancia con esta datación, así como lo contenido en el segundo punto, es imprescindible registrar, inventariar y catalogar los restos actuales del sistema de riegos de turbias.

- Averiguar las transformaciones que han afectado a la red hidrográfica, principalmente en su lecho principal, así como en el conjunto de la cuenca vertiente.

- Comparar el comportamiento del sistema con la dinámica ecoantrópica y con la "natural".

En este sentido, la rambla de Abanilla-Benferri representa un caso de estudio que no se ha dudado en calificar de paradigmático (Marco et al., 2020), gracias a un conjunto de circunstancias que confluyen en este curso fluvial que desemboca, de forma desorganizada y, en ocasiones, catastrófica, en el llano aluvial del río Segura. De hecho, en las inundaciones de septiembre de 2019, la crecida de la rambla generó graves consecuencias, principalmente en los términos municipales de Benferri y Orihuela, reabriendo un profundo debate técnico y político sobre las posibles soluciones a sus terribles inundaciones, aun cuando se conoce todavía poco sobre su funcionamiento y sus caudales punta y absolutos (Ortuño et al., 2020; Benadero et al., 2020). De hecho, se desconoce, incluso, la cantidad de agua que la rambla aportó en el referido episodio de 2019, aunque los cálculos de Benadero et al. (2020) arrojan un volumen total de $74,02 \mathrm{hm}^{3}$, con un caudal máximo estimado en $1.255 \mathrm{~m}^{3} / \mathrm{s}$ (que correspondería a un periodo de retorno levemente por encima de T300, según estos autores), aunque hay otras investigaciones que lo rebajan al entorno de $\operatorname{los} 600 \mathrm{~m}^{3} / \mathrm{s}$ (Oliva \& Olcina, 2021). Por otro lado, en los anejos del Plan de Gestión del Riesgo de Inundación de la Demarcación Hidrográfica del Segura, figura un caudal máximo de $358 \mathrm{~m}^{3} / \mathrm{s}$ para un periodo de retorno de T500 (CHS, 2015). Caudales, en todo caso, que tienen en cuenta la presencia del Canal de Abanilla, que desvía, desde finales de la década de 1960, parte de las crecidas al pantano de Santomera (Murcia). 


\section{Materiales y MÉTODO}

El enunciado de la hipótesis de trabajo parte de considerar que los sistemas fluviales surestinos han funcionado, multisecularmente, con una dinámica ecoantrópica debido, especialmente, a la implantación más o menos generalizada de sistemas de riego con aguas de avenida hasta fechas relativamente recientes; de manera que el abandono y la desarticulación de estos sistemas ha supuesto la implantación progresiva de una dinámica "natural" desde hace poco más (o menos) medio siglo. Esta transformación reciente, en buena lógica, determina el paso de un funcionamiento ecoantrópico, caracterizado por la derivación y laminación de una parte significativa de los caudales circulantes en los cauces de ríos, ramblas y barrancos, a un funcionamiento caracterizado por la "renaturalización", es decir, ante la ausencia de las detracciones del sistema de riego de turbias, un aumento de los caudales circulantes en dichos cauces. Y, por lo tanto, en un aumento de la peligrosidad de estas cuencas vertientes.

La comprobación o verificación de esta hipótesis, planteada para el conjunto de ramblas y cauces intermitentes del sureste peninsular, pasa, forzosamente, por abordar la serie de objetivos antes reseñados. Para ello, las fuentes utilizadas son diversas y muy numerosas, aunque sin apartarse de las que se han denominado en otras ocasiones, técnicas tradicionales de información geográfica (TTIG) (Marco, 2016). La recopilación de documentación y cartografía histórica resulta crucial para reconocer el comportamiento histórico del sistema fluvial y para constatar y datar los sistemas de derivación y conducción de las aguas. Una labor que cada vez resulta más complicada debido al progresivo deterioro y desaparición de dichos elementos e infraestructuras y, asimismo, por la pérdida de informadores que hayan conocido estos sistemas en pleno funcionamiento.

La recopilación e interpretación de la toponimia juega un papel transversal en todos los objetivos planteados, mientras que la fotointerpretación e información espacial y territorial generada han sido claves para elaborar la cartografía, que es herramienta y, al tiempo, uno de los resultados de la investigación. La determinación de la fecha de pérdida de funcionalidad del sistema, a falta de encuestas en los trabajos de campo, se ha basado en el análisis de la fotografía aérea disponible que comprende el periodo 1929-2020. Son un total de diecisiete vuelos distintos: 1929-1930, 1945, 1956, 1978, 1980 1986, 1987, 1993, 2002, 2005, 2007, 2009, 2012, 2014, 2017, 2018, 2019 y 2020. De toda esta información, sin embargo, cabe reseñar el interés del denominado "Vuelo de Ruíz de Alda" (1929-1930), realizado por la empresa CEFTA para la Confederación Hidrográfica del Segura (en adelante, CHS), que actualmente se halla disponible en forma de ortomosaico georreferenciado mediante conexión WMS. Los fotogramas se pueden visualizar y descargar, de forma individual, en los visores del ICV y del CNIG. Tratándose del documento fotogramétrico más antiguo de cuantos existen, presenta, además, un detalle excepcional (escala aproximada de $1: 18.000$ y $30 \mathrm{~cm}$ de píxel) y la oportunidad de que, entre los dos vuelos que lo componen, media un episodio de avenida que, a nuestro criterio, sería el del 10 de junio de 1929. Este hecho ha permitido comprobar, en parte, el funcionamiento del sistema y la determinación de las áreas de derrame, especialmente en las zonas distales de la extensa red de boqueras. 


\section{Área de estudio: la rambla de Abanilla-Benfferri}

La rambla de Abanilla-Benferri es la denominación que recibe el río Chícamo en su último tramo, aproximadamente a partir del límite de la provincia de Alicante con la Región de Murcia. Este curso fluvial, en su conjunto, recoge las escorrentías de la cuenca Fortuna-Abanilla, con relieves -sierras de la Pila, Quibas o Barinas- cercanos a los 1.000 m s.n.m., la cuenca de El Pinós-Alguenya -a través de la rambla de Vítia-, junto con los aportes procedentes de los glacis de la Sierra de Abanilla y los abanicos de la Sierra de Orihuela. Como se ha dicho, se trata de un excelente ejemplo de rambla mediterránea, tanto en su sentido hidrológico como geomorfológico, con caudales intermitentes, generalmente escasos, y crecidas de elevada magnitud y frecuencia, en ocasiones con volúmenes extraordinarios. Esta característica generó una singular adaptación de las sociedades humanas a esa naturaleza excesiva, relacionada con la escasez o el exceso de agua, atendiendo a un sistema en el que, al menos desde el último milenio, podría haber combinado la actividad hidrosedimentaria natural con la propia actividad antropogénica.

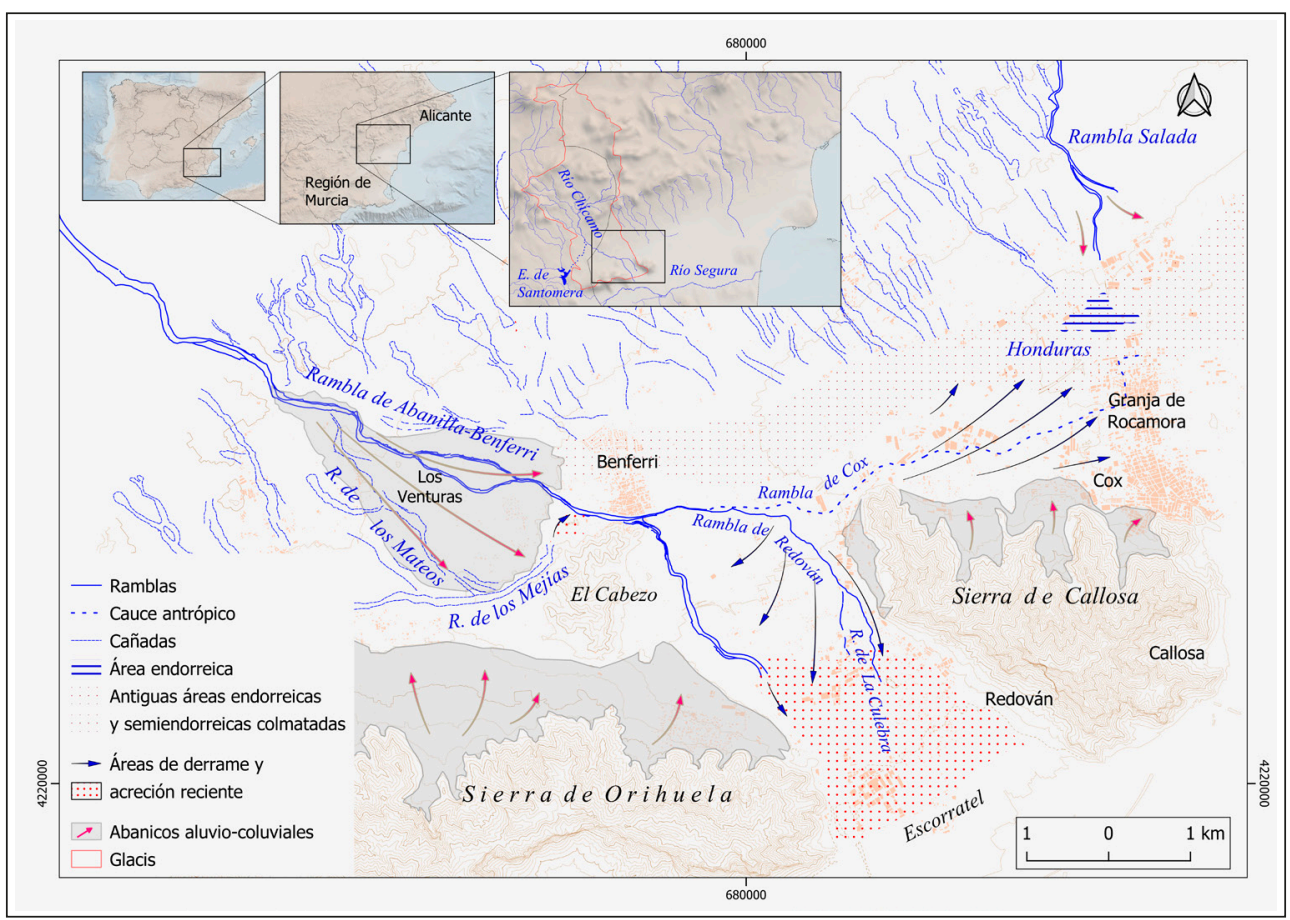

Figura 1. Localización y croquis geomorfológico del área de estudio. 
Desde el punto de vista geomorfológico (figura 1), una primera hipótesis interpretativa apunta a la importancia de la presencia de los Cabezos para entender la evolución del recorrido de la rambla de Abanilla-Benferri. En una fase previa, se podría haber formado un abanico aluvial que, en su fase de crecimiento, tendría como cauce principal la rambla de los Mateos, que intervendría actualmente como un paleocauce o cañada, activo en los episodios de mayor magnitud. Desde el ápice, con posterioridad, se abriría un nuevo cauce -la rambla actual- hasta los mencionados Cabezos, a partir de los cuales se produjo una acreción en forma de nuevos abanicos y áreas de derrame. Jerárquicamente, la principal área se establecería en el sector comprendido entre las sierras de Orihuela y Callosa, a partir de un cauce principal cuyo recorrido está determinado por la propia gravedad y que volvería a ser el que, actualmente, ha recuperado la rambla frente a Benferri, generando graves consecuencias en Orihuela. De manera secundaria, un brazo dirigiría las aguas de avenida hacia las ramblas de Redován y de la Culebra, generando un abanico con acreción histórica documentada, posiblemente impulsada por el propio sistema de boqueras. Todo este conjunto activaría, en los episodios más extremos, una escorrentía laminar en el tramo final que acabaría llegando al llano de inundación del Segura y, desde allí, a través de los azarbes de Abanilla y Mayayo -tal vez, antiguos paleocauces- hasta el sector más deprimido del llano aluvial, desecado en el s. xvin mediante las Pías Fundaciones. De vuelta a los Cabezos, la digitación del cauce hacia la rambla de Redován podría avenar ocasionalmente el sector norte de la Sierra de Callosa (Cox y Granja de Rocamora), un proceso que pudo incrementarse con la construcción y ampliación de una gran boquera que ha recibido el nombre de rambla de Cox; mientras que, en el caso de la de Redován, también existían elementos artificiales -presas o rafas-que ayudaban a dirigir el agua de crecida hacia sus lechos. De esta forma, cabe centrar el interés en este sector de difluencias de distintos cauces en el tramo final de la rambla, sector de notables conflictos hidráulicos e infraestructuras sorprendentes como la del Paredón de Benferri; pero sin olvidar que, aguas arriba, existía también un complejo sistema de presas de derivación que, desde Abanilla, venían laminando las avenidas, favoreciendo la sedimentación en los campos de cultivo situados a uno y otro lado del cauce y, en definitiva, controlando absolutamente el funcionamiento de la rambla durante siglos.

Efectivamente, en torno al río Chícamo existía un conjunto de asentamientos andalusíes, en forma de red de alquerías, que se consideran como fundadores del sistema de riego basado en el aprovechamiento de aguas de avenida (de Gea et al., 2012). Una hidráulica rural, previa a la conquista cristiana del s. xiII, sobre la que se fundamentó el crecimiento y desarrollo de sistemas hidráulicos posteriores. El Llibre de Repartimen d'Oriola (ss. XIII y xIV) resulta un documento demostrativo de la importancia de este tipo de riegos. En la segunda partición de 1268 se cita la alquería de Escorratel como beneficiaria de riegos de turbias, mientras que en la sexta y séptima particiones (1300-1314 y 1330, respectivamente) es cuando se indica el establecimiento masivo de nuevos colonos cristianos sobre este sector, aprovechando la organización rural previa. Se cita, por ejemplo, el azud de Benferri o la boquera de La Matanza, con lo que queda patente la consolidación y extensión del sistema en los ss. xiII y xiv, con posteriores ampliaciones. Cabe destacar la importancia de los ss. XV y xvi en la transformación y ampliación de estructuras hidráulicas (rafas, azudes y acequias) y de sistemas de reparto, en el marco del creciente poder señorial y de la agricultura comercial (de Gea et al., 2012). 
El aprovechamiento de las aguas y la instalación de presas en el cauce no estuvo exento de conflictos (Ojeda, 2011). Al menos desde 1467 "la rambla o acequia de Cox" (figura 1) tenía derecho para aprovechar las aguas de avenida, aunque la boquera era anterior y correspondía a esa organización medieval anteriormente aludida. Con la compra de Redován por la Orden de los Predicadores de Orihuela tras la expulsión de los moriscos en 1609, comenzaron los conflictos por el aprovechamiento de las aguas por parte de Cox, que se dirimió en diferentes pleitos hasta que, finalmente, en 1723, los Dominicos pusieron pleito al Señor de Cox y la Real Audiencia de Valencia falló, en 1748, a su favor: "aunque los Campos de Coix la huvieran tenido por mil años"1. La documentación generada por estos pleitos ha resultado de gran valor para reconstruir el funcionamiento del sistema de riego tradicional, que se amplió durante la Edad Moderna (especialmente hasta los inicios del s. XIx) y no sufrió cambios significativos hasta la segunda mitad del s. xx.

A finales de la década de 1960 se construyó una presa de derivación de las aguas de avenida, a través del canal de Abanilla, hacia el embalse de Santomera, con la intención de regular las crecidas de la rambla (Canales \& López, 2015). La puesta en marcha de esta infraestructura, junto con la llegada de caudales foráneos del trasvase Tajo-Segura, supuso importantes cambios paisajísticos relacionados con la expansión de la citricultura, la creación de nuevos parcelarios -muchos de los cuales ocuparon los bordes del cauce de la rambla, estrangulándolo- y la total desestructuración del sistema de riego tradicional (Hernández \& Giménez, 2011).

\section{Resultados}

\section{Reinterpretación de la cartografía y documentación histórica}

El motivo por el que resulta importante esta reinterpretación es identificar y localizar la mayor parte de los elementos del sistema. Cuestión absolutamente necesaria, puesto que existe cierta confusión cuando se indican algunos de esos elementos, incluido el que sería el cauce principal de la rambla aguas abajo de Benferri. Además, es la pieza clave para poder reconstruir el funcionamiento tradicional de la rambla en el contexto de esas dinámicas que hemos calificado como ecoantrópicas.

El referido pleito entre la Orden de los Predicadores y el señor de Cox, relativo al aprovechamiento de las aguas de avenida, se inició en 1725 y no se resolvió hasta 1748, aunque el conflicto continuó en las décadas siguientes. Fruto de este largo proceso son un conjunto de documentos y, en especial, de mapas, realizados en la primera mitad del s. xviı por agrimensores y técnicos contratados por una y otra parte, que definen muy bien el funcionamiento histórico de la rambla². Además de estos documentos

1 Alegación por el Colegio Patriarcal... (1759) (doc. trans. en Marín, 1997: 199)

2 Los mapas, datados entre la década de 1720 y 1743, se encuentran en el Archivo de la Catedral de Orihuela (ACO), Archivo Histórico de Orihuela (AHO) y en el Arxiu del Regne de València (ARV). Todos ellos son muy parecidos, aunque cada uno aporta pequeños detalles de gran valor informativo. El primero está reproducido por Gil Olcina \& Canales (1988: 202). El AHO se encuentra en la sección Mapas y Planos núm. 1, Rambla de Abanilla. En el ARV se conservan dos mapas, uno de los cuales aparece reproducido en Faus (1995: s.p.). 
vinculados al proceso aludido, también se han utilizado los bosquejos planimétricos (1897-1930), los primeros mapas impresos (MTN 50), diversos vuelos (1929-1930, 1945 y 1956, entre otros), así como las aportaciones de estudios locales y documentos transcritos (Marín, 1997; de Gea et al., 2012).

Con todo, la reconstrucción del sistema de derivación y riego con boqueras, de este tramo de la Rambla de Abanilla-Benferri, se ha basado, fundamentalmente, en la fotointerpretación llevada a cabo del vuelo de 1929-1930. Teniendo esta referencia como soporte básico, se han ido analizando cada uno de los planos, mapas y documentos en los que se reflejan o describen parte de los elementos del sistema.

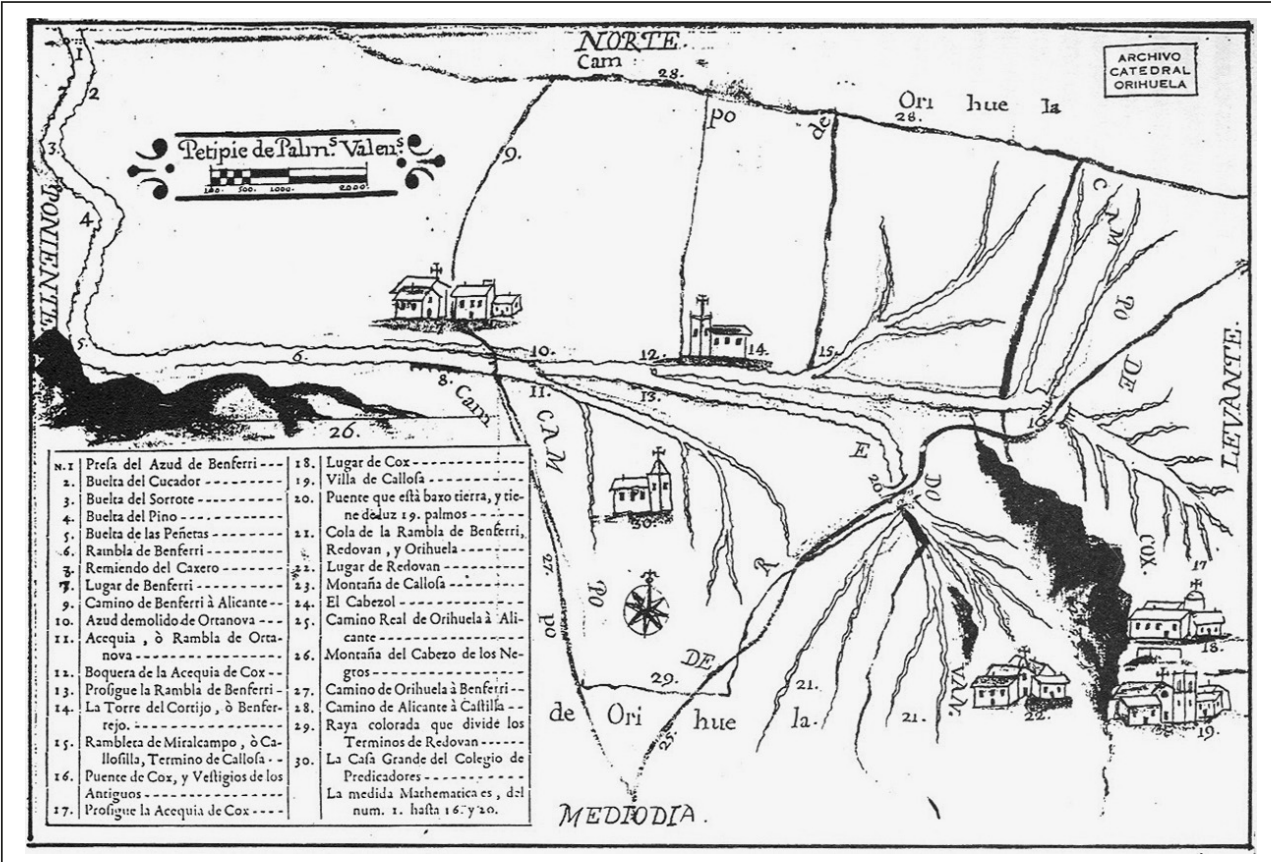

Figura 2. Área de estudio a principios del s. XVIII, mapa conservado en el Archivo de la Catedral de Orihuela (ACO).

Fuente: Reproducido por Gil \& Canales (1988: 202).

El análisis del plano-mapa que se encuentra en el ACO (figura 2) arroja los siguientes resultados:

- Los elementos destacados del relieve, representados con los números 23, 24 y 26 (figuras 2 y 3a), se identifican en la leyenda con "Montaña de Callosa", "El Cabezol" (solo permanece el topónimo de El Cabezo) y "Montaña del Cabezo de los Negros” (simplemente, El Cabezo, en el Nomenclàtor Toponímic Valencià).

- De las vías de comunicación e infraestructuras únicamente hemos considerado las que están señaladas con los números 16, 20, 25 y 27 (figuras 2 y 3a). Los dos primeros son 
puentes: "Puente de Cox, y Vestigios de los Antiguos" y "Puente que està baxo tierra, y tiene de luz 19 palmos"; mientras que los dos últimos son el "Camino Real de Orihuela à Alicante" (nacional) y el "Camino de Orihuela à Benferri".

- Los elementos del poblamiento han sido identificados en su totalidad, en especial, los núcleos de población, señalados con los números 7, 18, 19 y 22 del mapa (figuras 2 y 3a), que se corresponden con "Lugar de Benferri", "Lugar de Cox", "Villa de Callosa" y "Lugar de Redovan", respectivamente; mientras que los indicados con los números 14 y 30 son "La Torre del Cortijo, ò Benferrejo" y "La Casa Grande del Colegio de Predicadores" (figuras 2 y 3a), cuyo emplazamiento se infiere a través de la fotografía aérea de 1929-1930 y de la existencia del topónimo Casa Grande, respectivamente.

- Por lo que respecta a los cauces y su trazado, resaltan, aguas arriba de la zona en litigio, las curvas (designadas "bueltas" en el plano) que describe el curso de la rambla de Abanilla-Benferri (número 6 de las figuras 2 y 3a), con los números 2, 3, 4 y 5 (figuras 2 y 3a), recogidas en la leyenda como "Buelta del Cucador", "Buelta del Sorrote", "Buelta del Pino" y "Buelta de las Peñetas", respectivamente. Solo se ha identificado esta última con la inflexión que describe la rambla al aproximarse a El Cabezo, donde se encuentra el paraje denominado Las Peñetas y, a partir de este, se han situado las demás, hasta llegar al número 1 (figuras 2 y 3a), donde el plano coloca la "Presa del Azud de Benferri”, hoy en día, Los Partidores (4 de la figura 4). La rambla propiamente dicha, además del aludido número 6, también se recoge con el número 13 "Prosigue la Rambla de Benferri" y el 21 "Cola de la Rambla de Benferri, Redovan, y Orihuela" (figuras 2 y 3a), es decir, se concede el carácter de cauce principal a lo que hoy se conoce como rambla de Redován, la cual, junto con la rambla de la Culebra (un ramal difluente), constituyen la terminación o "Cola" de la rambla. En este apartado restan por reseñar los elementos indicados con los números 11, 12 y 15, que, respectivamente son: "Acequia, ò Rambla de Ortanova", "Boquera de la Acequia de Cox" y "Rambleta de Miralcampo, ò Callosilla, Termino de Callosa" (figuras 2 y 3a). El primero de ellos beneficiaría las tierras situadas alrededor de la Casa Grande y formaría parte de las reivindicaciones de los Predicadores; mientras que los otros dos eran los complejos de riego denunciados por ellos. El de Miralcampo, de reducidas dimensiones, no ha supuesto ningún tipo de impronta en la toponimia que haya llegado hasta la actualidad. En cambio, la entonces denominada "Acequia de Cox", seguramente para subrayar su carácter artificial de manera interesada por parte de los frailes, derivó en la toponimia en rambla de Cox y La Rambleta, en el sector más próximo a Granja de Rocamora, localidad que, extrañamente, no aparece representada (figuras 2 y 3 a).

- Por último, los elementos vinculados a la conducción y derivación de las aguas se limitan a los representados con los números 1,8 y 10 (figuras 2 y 3 a), que, respectivamente son la "Presa del Azud de Benferri" -hoy en día Los Partidores-, el "Remiendo del Caxero" -actual Paredón- y el "Azud demolido de Ortanova” (4, 10 y 11 de la figura 4). 


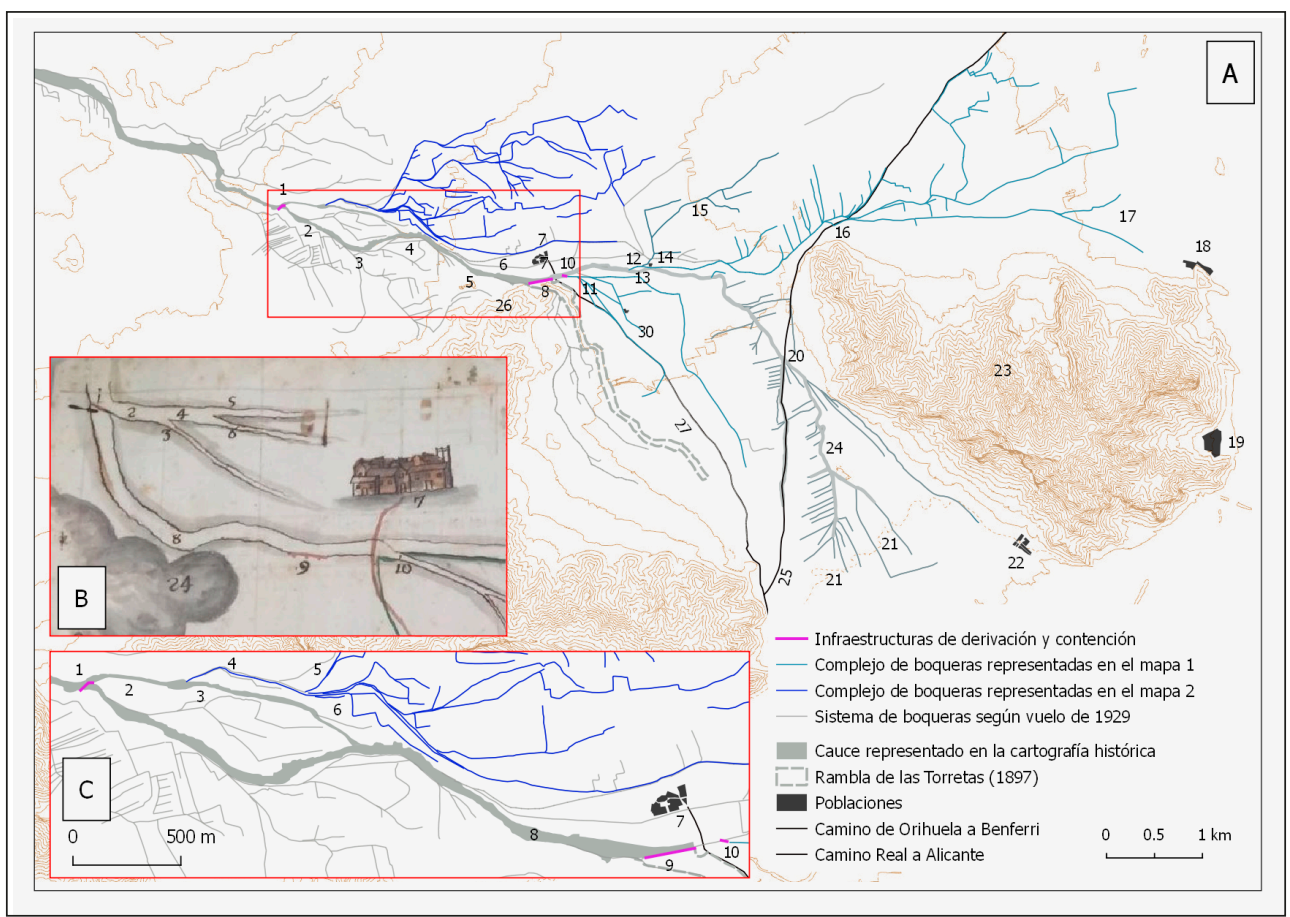

Figura 3. a) Reinterpretación del mapa del ACO (figura 2); $b$ ) detalle del plano del Archivo Histórico de Orihuela (localizado con recuadro en rojo) y $c$ ) transcripción a escala de los elementos reseñados en $b$.

El segundo plano-mapa analizado se encuentra en el Archivo Histórico de Orihuela (AHO), del que se reproduce un fragmento en la figura $3 \mathrm{~b}$ y c. A grandes rasgos, podría parecer que representa los mismos elementos que el anterior y, en gran medida, es así, pero, en realidad, tiene carencias y adiciones respecto a aquel. En esta ocasión se hará referencia a la información adicional que contiene, pues enumera los elementos más destacados que hay a continuación de la "Presa o Rafa de Benferri", es decir, a continuación de Los Partidores. Conviene recordar que, en este punto, la difluencia que se inicia termina por configurar una "isla fluvial", ya que aguas abajo, este ramal septentrional termina por confluir con el cauce principal de la rambla o ramal meridional.

De hecho, la asignación de cauce principal se toma de este mapa; puesto que, mientras que el ramal septentrional, indicado con el número 2, se califica como "(Sequia) de Benferri y Benferrejo", el meridional, con el número 8, es la "Rambla Comun de Benferri". A continuación, se representa una derivación, a partir de la cual, el ramal meridional, ahora indicado con el número 3, pasa a denominarse "Sequia del Sr. de Benferri"; mientras que el inicio de la derivación, con el número 4, se denomina "Cause Comun de Benferri y Benferrejo". Se trata, a tenor de lo observado en el Vuelo de Ruiz de Alda, de lo que se podría denominar un "boquerón" del que, a su vez, se inician dos de las boqueras más importantes del sistema: la "Sequia de Palazon", al norte, con el número 5, y la "Sequia del Conde”, con 
el número 6, más al sur. Se trata de las boqueras encargadas de beneficiar la mayor parte de las tierras de Benferri (figura 3 b y c).

Como se puede apreciar en la figura 3, restan por indicar todos los elementos de la margen derecha de la rambla, así como otras redes de boqueras en la margen izquierda; una, situada aguas arriba de Los Partidores; otra, que beneficiaba la "isla", y, la tercera, aguas abajo de la "isla" (Cañada del Conde). Asimismo, continúa pendiente el esclarecimiento de la evolución del llamado Paredón de Benferri y del papel que ha desempeñado.

Con todo, los complejos que completan el sistema, registrados a partir de las fuentes anteriormente descritas, son, por la margen izquierda, señaladas de arriba a abajo:

- La derivación desde el cauce que coincide con la llegada del llamado Qanat de la Fuente de las Anguilas o de Benferri (confines entre Alicante y Murcia), compuesto por dos boqueras principales que regaban las partidas más septentrionales del término de Benferri integradas en el sistema: La Venta, Los Buenos, Las Lomas de Alcofer y El Patrimonio (2 de la figura 4).

- El complejo presa de derivación-boquera que beneficiaba la Cañada del Conde, es decir, la "isla" fluvial (6 de la figura 4).

- Aguas abajo de la confluencia de los dos ramales de la rambla se encuentra el complejo presa de derivación-boquera o, como la denominan también de Gea et al. (2012: 207), acequia de Benferrejo, de la que se bifurca la denominada acequia del Olivar; que ceñían por el sur y norte, respectivamente, el núcleo de Benferri, al que atravesaban para llegar hasta Benferrejo y El Acembuchar (8 de la figura 4).

Por su parte, en la margen derecha, entre el límite con Abanilla y el Paredón de Benferri, se han localizado los siguientes elementos, enumerados a partir del que se encuentra aguas arriba:

- Pequeño complejo que beneficiaba las tierras situadas inmediatamente al norte de Las Casas Nuevas (Orihuela) (1 de la figura 4).

- Prácticamente por donde cruza la rambla el Camino de Alicante tiene su inicio una boquera que, más adelante, se bifurca para regar las tierras de Benferri de la partida de Los Venturas, es decir, las comprendidas entre el cauce de la rambla y el trazado de la llamada rambla de los Mateos (3 de la figura 4).

- Para cubrir el resto de las tierras comprendidas entre la rambla de Abanilla-Benferri y las ramblas de los Mateos-los Mejías, se estableció el complejo presa de derivación-acequia, denominada de Doñana por de Gea et al. (2012: 207) (7 de la figura 4).

- Y, por último, inmediatamente aguas arriba del Paredón se advierte la presencia de otra derivación que, situada al norte de El Cabezo, se continúa por una boquera que termina beneficiando el paraje de Lo Ros (Orihuela) (9 de la figura 4).

De este modo se ha podido completar la red de boqueras y superficie beneficiada con las aguas de avenida derivadas de la rambla de Abanilla-Benferri en la provincia de Alicante (figura 4). Este resultado de la investigación, verdadera piedra angular para la comprobación de la hipótesis planteada, es 
asimismo, detonante para el planteamiento y desarrollo de varias líneas o hipótesis específicas sobre determinados aspectos del sistema y su funcionamiento.

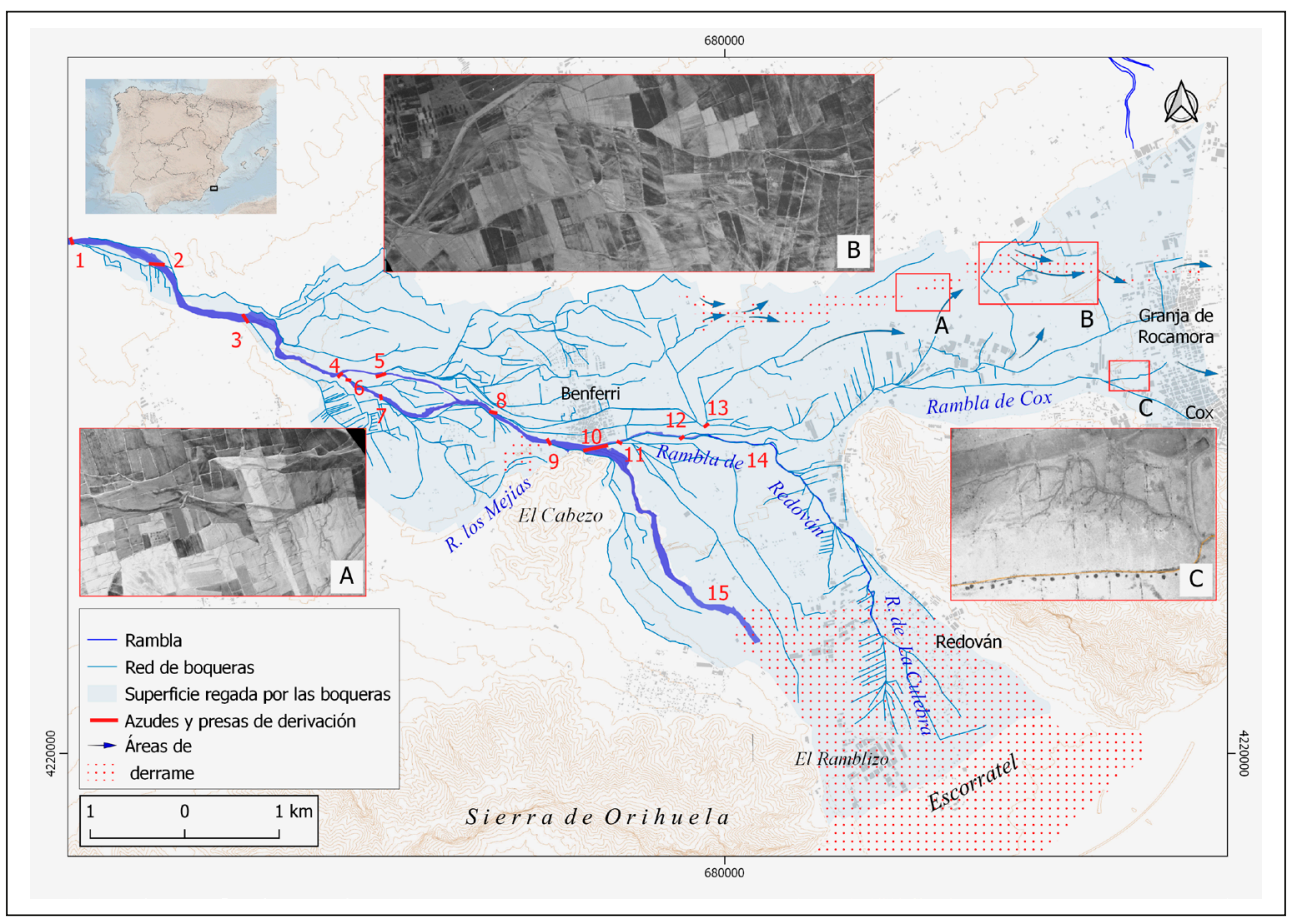

Figura 4. Red de presas y boqueras con la superficie beneficiada por el riego. Se presentan detalles de fotogramas del vuelo de 1929-1930 donde se reconocen áreas de derrames (A, B y C). Elementos del sistema: 1. Complejo del norte de Casas Nuevas (Orihuela). 2. Derivación de las partidas septentrionales de Benferri: La Venta, Los Buenos, Las Lomas de Alcofer y El Patrimonio. 3. Boquera o Rambla de los Venturas. 4. Los Partidores. 5. Derivación de las boqueras de Palazón y del Conde. 6. Derivación de la Cañada del Conde. 7. Derivación de Doñana. 8. Derivación de Benferrejo y El Acembuchar. 9. Derivación de Lo Ros (Orihuela). 10. El Paredón. 11. Derivación o azud de Horta Nova. 12. Derivación de la Rambla de Cox. 13. Derivación de Miralcampo o la Callosilla. 14. Rambla de Redován-la Culebra. 15. Cauce de la Rambla de Abanilla-Benferri aguas debajo de El Paredón.

El funcionamiento del sistema: la dinámica ecoantrópica y sus desajustes

En realidad, el establecimiento de todo el conjunto de complejos de derivación y boqueras descrito supone la implantación de una dinámica ecoantrópica ligada al control y aprovechamiento de la principal característica de estas cuencas vertientes y sistemas fluviales del sureste peninsular, es decir, su comportamiento espasmódico, marcado por la recurrencia de episodios de avenida o riadas súbitas 
(flash flood) que, por definición, están ligadas a episodios de lluvias torrenciales. De este modo, se cumple un doble objetivo: aminorar las consecuencias perniciosas de las riadas y aprovechar un recurso, el agua, en un dominio en el que es muy escaso. Casi se podría decir que este conocimiento tradicional relativo al aprovechamiento de las aguas de avenida se fundamenta, firmemente, en criterios de sustentabilidad. Es de suponer que el sistema se concibe, aunque sea de manera instintiva, con la capacidad suficiente como para asumir o asimilar ese comportamiento espasmódico.

Es evidente que esta idea obvia otra característica del comportamiento de las ramblas, la variabilidad en la magnitud de las riadas y, sobre todo, la existencia de eventos extremos. No obstante, a la vista de la figura 4, también es obvio que el funcionamiento de la rambla estaba mayormente controlado mediante la laminación de sus crecidas, de tal manera que en los extremos distales del sistema difluente que supone la implantación del riego con boqueras de las aguas de avenida, esta laminación se distribuía en una superficie aproximada de 2.820 ha, a partir de catorce complejos de derivación, distribuidos en ambas márgenes.

En la hipótesis manejada cabe, como planteamiento concreto, la idea de que este sistema de derivación y laminación tenía una capacidad idónea para asumir avenidas cuya magnitud se podría denominar de moderada a ordinaria. Sin embargo, se trata de un sistema que, intencionadamente o no, poseía "válvulas" de escape para descongestionar el sistema cuando la magnitud de las aguas circulantes excedía la capacidad aludida. De hecho, en el mapa del ACO (figura 2) no deja de llamar la atención la forma de representar las terminaciones de la rambla (acequia) de Cox y de la rambla de Redován; en especial la de esta segunda, que se identifica como "Cola de la Rambla de Benferri, Redovan, y Orihuela" (21 de las figuras 2 y 3a), a modo de redes divergentes bien explícitas. Es por ello que estas zonas distales de la red, que actúan de válvulas, se han conceptuado como áreas de derrame (figura 4). Carácter que también presenta, aunque con menores dimensiones, el complejo del azud de Horta Nova, en el entorno de la Casa Grande (de los Predicadores) (10 y 11 de la figura 3a; 11 de la figura 4). En cualquier caso, este espacio entre las sierras de Callosa, al este, y la de Orihuela, a occidente, se presenta como una de las salidas naturales de la rambla de Abanilla-Benferri hacia el llano de inundación del río Segura, lo cual no quiere decir que conectara con él, bien podía desaguar en sectores que fueran endorreicos o semiendorreicos. Algo parecido se puede plantear con el otro gran ramal terminal de la rambla, es decir, el que se dirigía hacia Cox-Granja de Rocamora (17 de las figuras 2 y 3a), puesto que hacia el este de estas localidades se sitúan varios sectores de difícil avenamiento, cuando no enteramente endorreicos.

Pero, volviendo al lugar por donde desagua la rambla de Redován, otros elementos refuerzan la idea de área de derrame o área con derrames múltiples, como ya se ha insinuado. Este sector entre las sierras de Callosa y Orihuela aparece citado por Cavanilles (1797: 290) con el topónimo Els Ramblars, que no aparece en la actualidad, pero basta con analizar la toponimia de la zona para convenir que no le faltaba fundamento. En la actualidad, los hidrónimos que se mantienen son: la Rambla de Redován y la Rambla de la Culebra, ambas en término municipal de Redován, mientras que, en término de Orihuela, se señala La Rambla; coincidiendo todos con aquella "Cola de la Rambla de Benferri, Redovan, y Orihuela” del mapa del ACO. Además, también registra el Nomenclàtor Toponímic Valencià, El Ramblar, en el área que regaban las boqueras del azud de Horta Nova (Casa Grande de los 
Predicadores) y El Ramblizo, donde irían a parar las aguas "extraviadas" desde el Paredón (figura 4); asunto, este último, que merece un capítulo aparte.

Para el resto del sistema ha sido muy importante la oportunidad de la fecha de buena parte de los fotogramas del Vuelo de Ruiz de Alda, ya que parte de los fotogramas, a falta de confirmar en archivo, se obtuvieron poco tiempo después de una avenida. Se está haciendo referencia a la ocurrida a principios de junio de 1929. Bancales anegados o enlamados, flujos marcados por la humedad o los efectos de la erosión en surcos-gullies (ramblizos), son los elementos que han servido para identificar y localizar (georreferenciar) las áreas de derrame localizadas en los sectores este y nordeste, hacia Cox, Granja de Rocamora y Albatera (figura 4).

\section{El Paredón de Benferri}

Como se ha visto en la cartografía histórica, el conocido como Paredón de Benferri ( 8 de las figuras 2 y 3a; 9 de las figuras 3b y 3c; 10 de la figura 4), que "no es boquera, presa ni azud" (1759)33 cumplía un papel nuclear en la organización del último tramo del sistema hidráulico, a modo de gran infraestructura de derivación y, a su vez, de muro de defensa que trataba de impedir la circulación de las aguas hacia el sur. Como bien se señala a mediados del s. xvinI, "la obra del Paredon no se hacia en el cauce de la rambla, de fuerte, que embarazase el curso del agua, antes bien se ordenaba à que no huviesse extravio". Se entiende, en esta descripción, que el susodicho extravío se referiría, en realidad, a la tendencia natural del agua a dirigirse hacia el sur, antes de que, en algún momento del pasado, se dirigiera hacia el este.

Según de Gea et al. (2012), la obra podría tener precedentes islámicos y aparece mencionada en el s. XIII, aunque sus reparaciones y ampliaciones parecen constantes. En la misma documentación del s. XVIII anteriormente referida, se habla de una "Mota (que estava en el sitio donde aora se halla el Paredón)" que fue reforzada, en distintas fases, a lo largo de dicho siglo. De hecho, en la cartografía se señala un "remiendo del caxero", bien expresivo, en el lugar donde se sitúa el Paredón. Este enorme muro de $253 \mathrm{~m}$ de longitud, que supera en algunos tramos los $10 \mathrm{~m}$ de altura, resultaba una pieza fundamental no solo para garantizar el funcionamiento de las boqueras o ramblas de Cox y Redován, sino para la seguridad de gran parte de la Vega Baja del Segura y, muy especialmente, del núcleo de Benferri (figura 5).

3 Alegación por el Colegio Patriarcal... (1759) (trans. en Marín, 1997: 204-207). En similares términos para las transcripciones siguientes. 


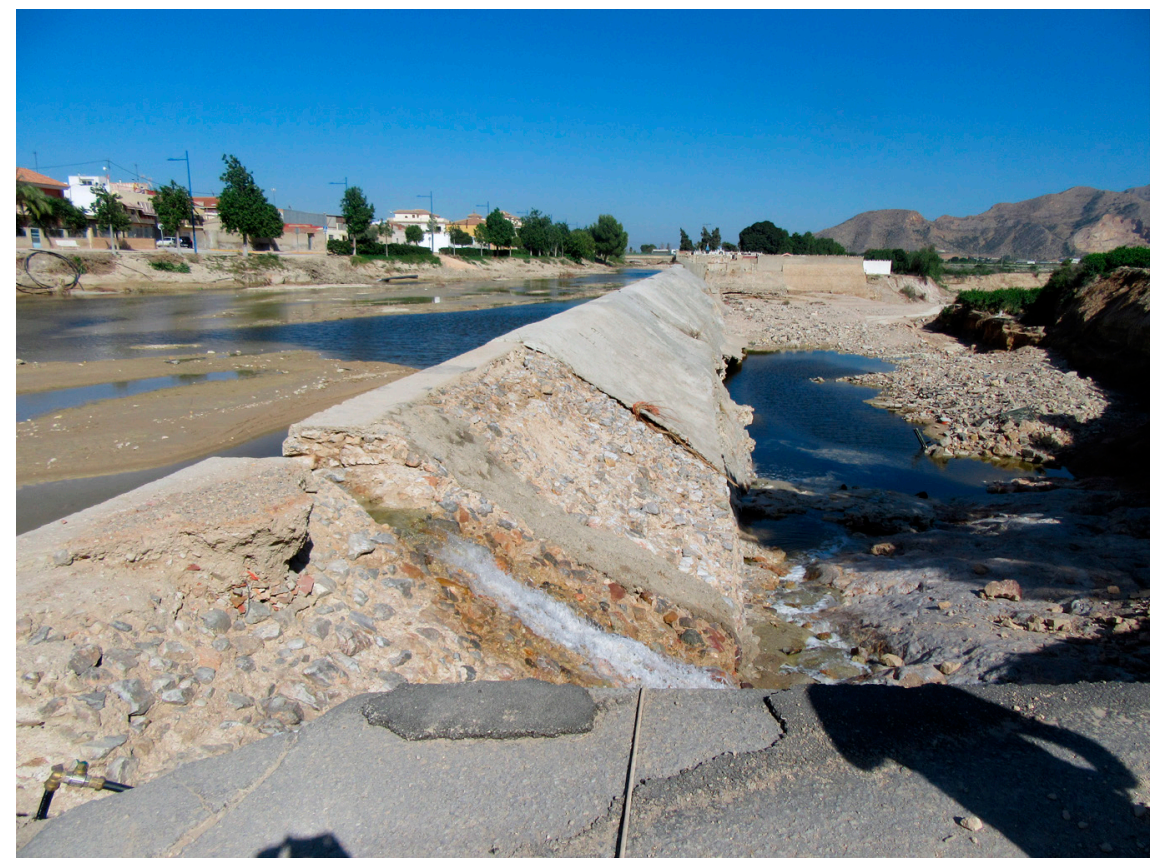

Figura 5. El Paredón en el año 2020, meses después de la crecida de septiembre de 2019. Se puede apreciar la diferencia entre el nivel del cauce aguas arriba y la base de la presa, fruto de la retención histórica de sedimentos

De forma cada vez menos excepcional, las aguas de crecida superaban el paredón e inundaban parte del barrio de San Antón, donde se sitúa el Palmeral de Orihuela, en las inmediaciones de la puerta este de la ciudad (Puerta de la Olma). Los problemas no derivaban tanto de la avenida e inundación como del estancamiento de las aguas. En 1643, 1648 y 1650 existen noticias sobre la preocupación de la ciudad ante las epidemias de malaria producidas por las lagunas generadas tras avenidas de la rambla y el aterramiento del actual azarbe de la Fuente, junto con la multiplicación de balsas de cocer cáñamo (Bernabé, 1999).

Durante la segunda mitad del s. XviII su estado de conservación era muy deficiente y se realizaron costosas obras de mejora "de la pared vieja”, dirigidas por el arquitecto Miguel Francia. Los responsables de financiar las obras, que se prolongaron durante décadas por problemas económicos, dan una idea de la importancia de la infraestructura: en 1779 existía una junta presidida por el Obispo de Orihuela, con los señores de Cox y Redován, un "Síndico del Ramblar” y un Comisario General de la Huerta, encargado este último de cobrar las deudas de los regantes del azarbe de Mayayo. Este azarbe, que junto con el de Abanilla es el más importante de la margen izquierda del Segura en su Vega Baja, concentraban las aguas de las avenidas extraordinarias que la rambla de Abanilla-Benferri y las dirigía hacia los sectores más deprimidos del llano de inundación. En 1759, sin que haya trascendido una avenida 
importante del río Segura durante dicho año, se produjo un acontecimiento extraordinario: "las aguas de esta Rambla, por ser de avenida, con el riguroso ímpetu en tiempos pasados hicieron una gran rotura [refiriéndose al Paredón], extraviando su curso regular, con lo que [...] ocasionó el rompimiento, y extravío de las aguas, que dexaron su regular antiguo curso, tomando sus corrientes á las tierras de la Huerta de esta Ciudad [Orihuela], Lugar de Rafál, y villas de Callosa, Dolores y demás de las pías fundaciones" (Nipho, 1770: 311). Es posible que, tras este episodio singular de 1759, que la documentación señala como un momento de inflexión en el comportamiento de la rambla al dañarse seriamente el Paredón, se iniciaran los intentos de reparación descritos anteriormente, que tras la turbulenta década de 1770 -en lo que al clima se refiere (Alberola, 2014) - no habían sido suficientemente atendidos:

Que por esta omición se havia verficado en las imediatas avenidas haver sobrepujado las aguas la altura de la Pared, y á su caida desmoronado el resfuerzo de la antigua, y socavando en muchas partes la nueva, assí por faltar á aquel la solidez, y consistencia proyectada. Como por no estar ya toda enlusida, y revocada para despedir las aguas como lo haría en el caso contrario: Que los perjuicios [...] se miravan forsosos, y temibles que qualquier otra avenida rompiese la Pared ya quebrantada, con pérdida de los caudales imbertidos en ella, y la maior de inundar la Huerta y perder la preciosa cosecha (de Gea et al., 2012: 291).

No obstante lo expuesto, resulta llamativa su omisión en los mapas analizados del s. Xvin. La única referencia recogida en estos es la de "Remiendo del caxero". A pesar de todo, cada vez que se menciona la rambla de Abanilla-Benferri con motivo de riadas, es este el cauce que resulta más dañino, es decir, el que se desarrolla aguas abajo de El Paredón. De hecho, tanto en la documentación antigua consultada como en las relaciones de episodios de avenidas nunca se menciona el otro ramal que supuestamente constituye otra terminación del sistema fluvial o rambla de Redován y al que se le concede el papel de cauce principal.

La primera representación del cauce que se desarrolla aguas abajo de El Paredón se ha hallado en los Bosquejos planimétricos del término municipal de Orihuela (1897) (figura 6A), con la denominación de Rambla de la Torreta, una anchura media de 40 m y representada con doble trazo azul discontinuo, llegando hasta la Carretera de Orihuela a Abanilla (CV-8702), en el paraje de los Regueros (Las Torretas en el Nomenclàtor Toponímic Valencià). En el vuelo de 1929-1930 se aprecia este cauce de manera muy nítida y, si acaso, con una anchura algo mayor (figura 6C). Sin embargo, el aspecto más interesante que se observa en los fotogramas es, por un lado, que el cauce termina aguas abajo de la carretera mencionada; y, por otro, que, en el último tramo, ese cauce está acondicionado como cañada, es decir, convertido en bancales. En los fotogramas de 1945 prácticamente se reproduce la situación descrita, pero en 1956, el aluvión llega casi hasta la carretera CV-8702; ya han mediado varios eventos y, en especial, el de 1947, que "asoló el cementerio de Benferri" (tabla 1).

Por último, no deja de ser llamativo que en las minutas correspondientes a los trabajos topográficos previos a la publicación del MTN 1:50.000 (figura 6B) se obviara la presencia de este cauce, que no se representa en la primera edición del MTN (1933), a pesar de ya estar dibujado en los bosquejos de finales del s. XIx (figura 6A). 


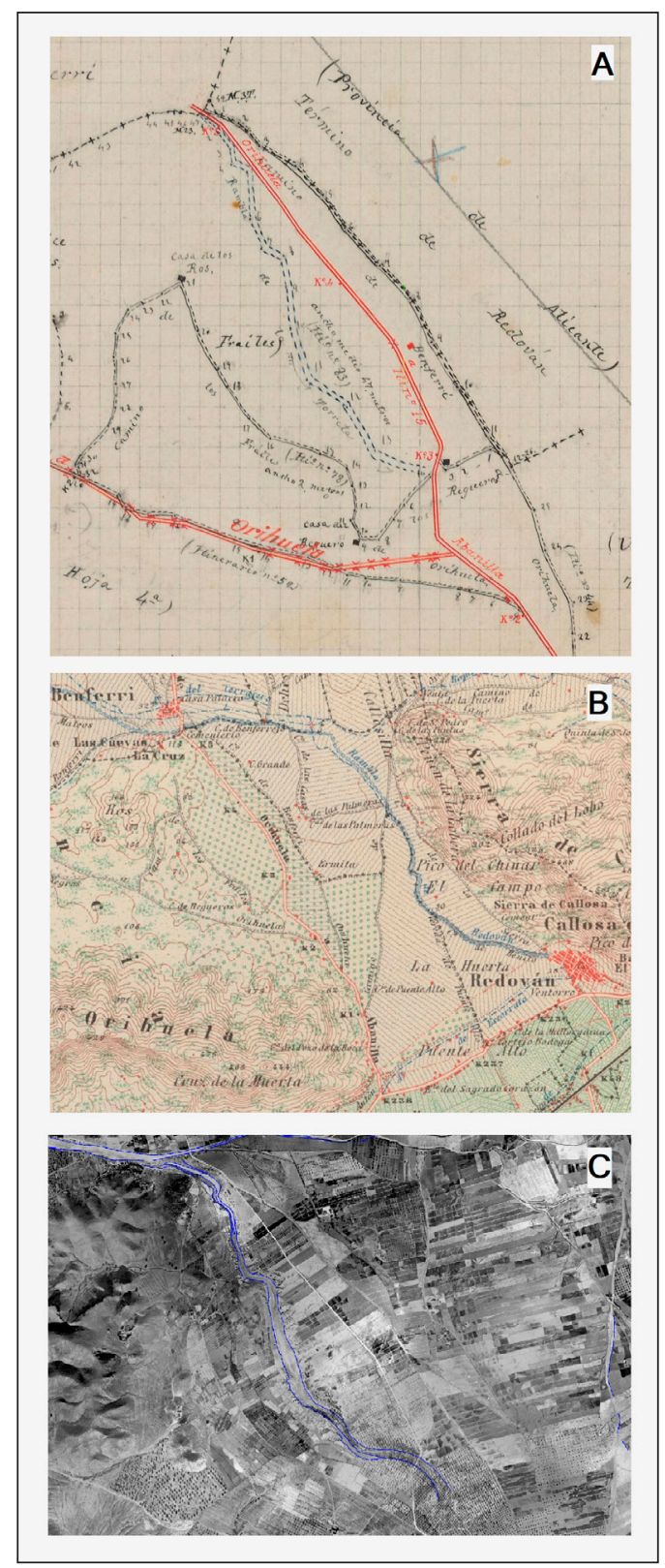

Figura 6. Representación del cauce aguas abajo del Paredón: A) dibujado como "Rambla de la Torreta" en un Bosquejo planimétrico de 1897; B) cauce obviado en la primera edición del MTN (1933), en la que únicamente aparece la rambla de Redován; y C) perfilado con línea azul, se aprecian las dimensiones del cauce fotografiado por Ruiz de Alda en 1929-1930. Fuente: CNIG. 


\section{Transformaciones recientes y desorganización del sistema}

Tratar de determinar hasta qué momento se han mantenido operativos los sistemas de derivación resulta crucial en la comprensión del funcionamiento actual de estas cuencas vertientes. Sin embargo, es obligado registrar, inventariar y catalogar los restos actuales del sistema de riegos de turbias, especialmente cuando están constatadas a partir de la documentación y cartografía histórica, o bien a través de la fotointerpretación, especialmente, del vuelo de 1929-1930.

El sistema está integrado tanto por complejos presa de derivación-boquera, como por boqueras que se inician directamente en el lecho de la rambla, identificadas con las denominadas en "malecón" por Morales (1969). En ocasiones, si hubo algún tipo de estructura para derivar los caudales, no se aprecian en la fotografía aérea, probablemente porque serían simples diques o ribazos de tierra y cantos o, incluso, simples "atochadas"; posibilidad recogida en disposiciones legales tan recientes como la Ley de Aguas de 1985 (Morales et al., 1989) o en la tradición oral de cuencas próximas como la rambla de Sarsa-El Derramador (Agost).

Para determinar el momento en el que el sistema perdió su funcionalidad, se ha analizado la fotografía aérea y las ortofotos disponibles entre el periodo 1929-2020, tal y como se ha descrito en el apartado de materiales y método. La observación se ha aplicado, inicialmente, a uno de los elementos del sistema, la conocida presa de derivación o rafa de Benferrejo ( 8 de la figura 4), situada aguas abajo de la "isla".

El análisis ha puesto el foco en tres aspectos que se han considerado esenciales para poder concluir el momento aproximado en el que el sistema deja de ser efectivo: la estructura de derivación, las boqueras y, en otro plano, la cobertura vegetal de cauce y boqueras. Así, la funcionalidad del sistema, claramente identificable en los fotogramas de 1929-1930 (figura 7A), se mantiene, sin lugar a dudas, hasta los fotogramas de 1956, siendo perfectamente reconocibles la presa, el inicio de la boquera y su muro, dispuesto en paralelo al cauce, así como su continuación. En este periodo la cobertura de la vegetación se mantiene en mínimos, tanto en el cauce como en las boqueras. En 1978, a pesar de poder identificar los elementos del sistema, se aprecia un aumento de la cubierta vegetal, especialmente en las boqueras; situación que da idea de escasa funcionalidad del sistema; al tiempo que se observan los primeros cambios en los usos del suelo, vinculados, sin duda, a la llegada de caudales foráneos (trasvase Tajo-Segura) y la transformación a una citricultura de regadío. Con todo, los caudales derivados de la rambla han perdido su sentido y a partir del fotograma de 1984, el taponamiento y la colmatación de las boqueras, entonces parcial, es casi completo a partir de los fotogramas de 1987. De forma paralela, la incipiente transformación a regadío se ha ido completando hasta convertirse, prácticamente, en un monocultivo de cítricos. Se puede concluir, pues, que la pérdida de funcionalidad de este complejo de derivación debió producirse en fechas anteriores a 1984. Probablemente sea esta la fecha que se podría aplicar al conjunto del sistema, pero la constatación de que el proceso de desmantelamiento y desorganización del sistema no tiene por qué ser homogéneo la ofrece una referencia de 1967 para el caso concreto de la rambla de Cox. De Gea et al. (2012) dan a entender que la reiteración de avenidas (tabla 1) en la zona de derrame de Redován, Escorratel y barrio de San Antón provocó un intento de reapertura 
del "cegado cauce de la antigua acequia o rambleta del campo hacia Cox, Granja de Rocamora y los Saladares de Albatera", que había sido parcialmente taponado en la década de 1940.

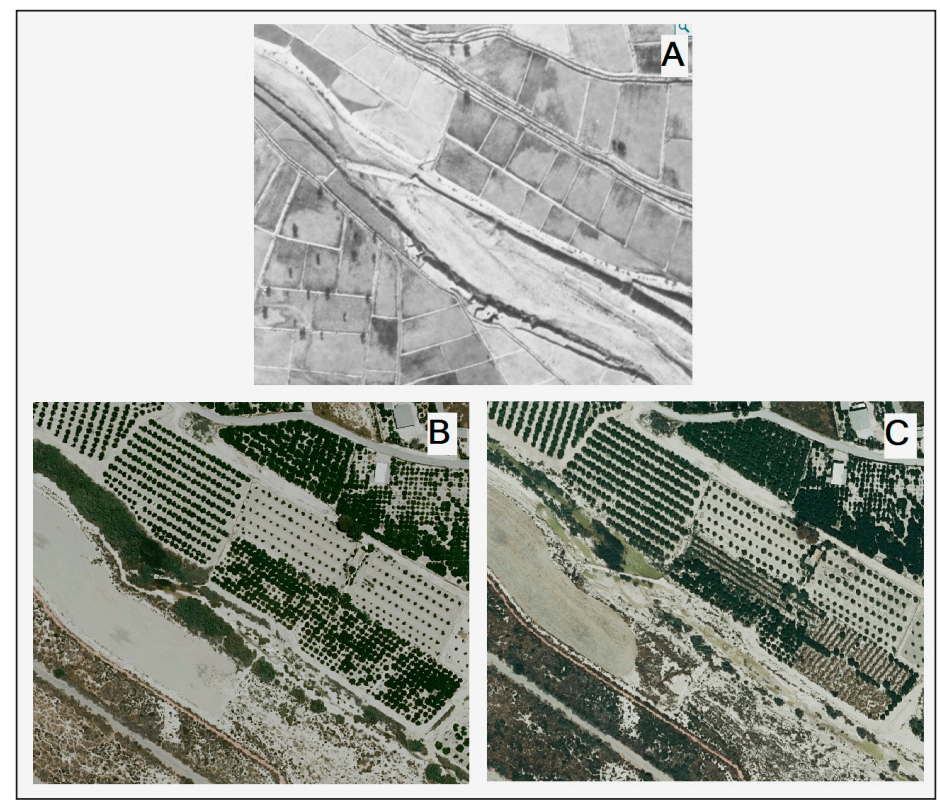

Figura 7. Evolución de la presa de Benferrejo: A) 1929-1930; B) ortofoto de 2019, previa a la avenida de septiembre de ese mismo año; y C) ortofoto de 2020.

Fuente: Fototeca del Institut Cartogràfic Valencià.

Tabla 1. Episodios de avenida en los ss. xx y xxı. En gris, aquellos eventos en los que no aparece de manera explícita la rambla de Abanilla-Benferri. Elaboración propia a partir de las distintas fuentes citadas.

\begin{tabular}{|c|l|}
\hline Fecha & \multicolumn{1}{c|}{ Observaciones } \\
\hline ¿?/09/1905 & $\begin{array}{l}\text { En Orihuela causó alarma el ímpetu de la corriente del Segura, incrementada con las } \\
\text { aportaciones de las ramblas afluentes (CNPC, 1983) }\end{array}$ \\
\hline 25/09/1906 & Inundación de Santomera (24 muertos) (CNPC, 1983) \\
\hline ¿?/09/1910 & $\begin{array}{l}\text { En Orihuela los daños ocasionados por el desbordamiento de cauces fueron inmensos (CNPC, } \\
1983)\end{array}$ \\
\hline i?/11/1916 & La huerta de Orihuela, anegada por desbordamiento de ramblas y río (CNPC, 1983) \\
\hline ¿?/09/1919 & Entre Albatera y Crevillente, destrozos en la vía férrea (CNPC, 1983) \\
\hline ¿?/11/1926 & En Orihuela las lluvias hicieron salir de madre las ramblas y barrancos (CNPC, 1983) \\
\hline
\end{tabular}




\begin{tabular}{|c|c|}
\hline Fecha & Observaciones \\
\hline $\begin{array}{l}11 / 06 / 1929 \\
12 / 06 / 1929\end{array}$ & $\begin{array}{l}\text { Barrancos y ramblas desbordados anegaron bancales y destrozaron caminos. También salieron de } \\
\text { madre las ramblas Salada, Cabezo de la Plata, Torreagüera y Churra (CNPC, 1983) }\end{array}$ \\
\hline $25 / 12 / 1931$ & Salió de madre la rambla de Santomera (CNPC, 1983) \\
\hline $23 / 04 / 1946$ & $\begin{array}{l}\text { Inundación de la vega entre Orihuela y Guardamar: Orihuela, Rojales, Dolores, Almoradí, } \\
\text { Bigastro, Rafal y caseríos. Avenidas de las ramblas de Abanilla-Benferri, Santomera y La } \\
\text { Muda. Hasta } 2 \text { m, } 23.600 \text { ha entre Orihuela y Guardamar; } 200.000 \text { tahúllas, de ellas, } 85.000 \\
\text { correspondían a Orihuela. Dolores, Rafal y San Fulgencio fueron evacuados (CHS) }\end{array}$ \\
\hline 29/09/1947 & $\begin{array}{l}\text { Inundaciones desde Monteagudo hasta Guardamar. Avenidas de las ramblas de Santomera y } \\
\text { Abanilla-Benferri. En la zona de Orihuela la rambla de Abanilla-Benferri adquirió un nivel } \\
\text { superior en 1,30 m al de otras avenidas conocidas, de forma que inundó la parte honda de la } \\
\text { huerta (CNPC, } 1983 \text { y De Gea et al. 2012) } \\
\text { La rambla de Abanilla-Benferri dejó inundadas zonas de huerta y anegó el pueblo de Benferri, } \\
\text { cuyo cementerio quedó asolado por el ímpetu de las aguas (CHS) }\end{array}$ \\
\hline 23/03/1949 & Crecidas en las ramblas Salada (Santomera) y Abanilla-Benferri (CHS) \\
\hline $07 / 10 / 1950$ & $\begin{array}{l}\text { Desbordamiento del Segura en Orihuela, alcanzando el agua una altura en sus calles de } 70 \mathrm{~cm} \text {. } \\
\text { Las avenidas en las ramblas Salada (Santomera) y Abanilla-Benferri inundaron } 5.000 \text { tahullas } \\
\text { de la Vega Baja (CHS) }\end{array}$ \\
\hline $\begin{array}{l}17 / 10 / 1957 \\
18 / 10 / 1957\end{array}$ & $\begin{array}{l}\text { Crecidas de las ramblas de Santomera y Abanilla-Benferri, aunque no hubo inundaciones por } \\
\text { falta de sincronización de las ramblas. Demanda de construcción de un embalse en la rambla de } \\
\text { Santomera (Juárez et al, 1989) }\end{array}$ \\
\hline $\begin{array}{l}17 / 12 / 1964 \\
19 / 12 / 1964 \\
22 / 12 / 1964\end{array}$ & $\begin{array}{l}\text { Se inundaron Orihuela, San Fulgencio y Guardamar, así como } 670 \text { ha en San Fulgencio y } \\
\text { Guardamar. Avenidas de las ramblas de la Vega Baja del Segura (CHS) }\end{array}$ \\
\hline $\begin{array}{l}08 / 12 / 1965 \\
11 / 12 / 1965\end{array}$ & $\begin{array}{l}\text { Inundación de la Huerta de Orihuela, Molins y San Bartolomé, Bigastro, Jacarilla, (Benferri), } \\
\text { Hurchillo y Guardamar. Riadas de los torrentes en Callosa de Segura, Abanilla-Benferri, Bigastro } \\
\text { y Jacarilla. Torrentes en Callosa de Segura: toneladas de piedra y tierra a gran velocidad (debris } \\
\text { flow). Rambla de Abanilla-Benferri: las aguas alcanzaron 2,5 m, anegaron un buen trecho de la } \\
\text { carretera de Murcia y el Palmeral de San Antón, en Orihuela (Juárez et al, 1989) }\end{array}$ \\
\hline 14/09/1966 & $\begin{array}{l}\text { Avenidas de las ramblas de Santomera y Abanilla-Benferri. Se desbordó la rambla de Abanilla- } \\
\text { Benferri y las aguas cubrieron la carretera general en el tramo comprendido entre el PK 25,7 } \\
\text { (Orihuela) y el PK } 34 \text { (Albatera). Las aguas inundaron extensas zonas de La Murada, Benferri, } \\
\text { Callosa de Segura, Redován y Orihuela. En Orihuela se inundó gran parte del Palmeral de San } \\
\text { Antón (CNPC, 1983) }\end{array}$ \\
\hline 10/10/1966 & $\begin{array}{l}\text { Avenidas de los ríos Segura y Guadalentín y de la rambla de Abanilla-Benferri. Quedaron } \\
\text { anegadas zonas de San Fulgencio, Rojales y Guardamar. Se desbordó la rambla de Abanilla- } \\
\text { Benferri, inundando zonas de la huerta de Orihuela (CHS) }\end{array}$ \\
\hline $16 / 04 / 1967$ & Avenida de la rambla de Abanilla-Benferri (CHS) \\
\hline $\begin{array}{l}02 / 11 / 1987 \\
06 / 11 / 1987\end{array}$ & $\begin{array}{l}\text { Inundación de toda la huerta. No hay noticias, a pesar de que en Callosa volvió a quedar } \\
\text { sepultada la rambla (Giménez Font, 2006). Tampoco se recogen noticias de la rambla de } \\
\text { Abanilla-Benferri, que también experimentó una riada que rebasó el Paredón (fotos en de Gea } \\
\text { et al., 2012) }\end{array}$ \\
\hline
\end{tabular}




\begin{tabular}{|c|l|}
\hline Fecha & \multicolumn{1}{|c|}{ Observaciones } \\
\hline $12 / 09 / 2019$ & La llamada Riada de Santa María, catalogada como de las más catastróficas y devastadoras. Se \\
$14 / 09 / 2019$ & $\begin{array}{l}\text { produjeron inundaciones de gran extensión en las Vegas Media y Baja del río Segura (de más de } \\
500 \mathrm{~km}^{2} \text { ). El municipio de Orihuela también se vio gravemente afectado por el desbordamiento } \\
\text { de la rambla de Abanilla (CHS). }\end{array}$ \\
\hline
\end{tabular}

De los elementos del complejo, solo han llegado hasta la actualidad los restos de la presa de derivación, mientras que las boqueras han desaparecido en todo su trazado, convertidas en caminos o reducidas a meros linderos entre parcelas e, incluso, sustituidas por el callejero del núcleo de población de Benferri.

Por su parte, en el cauce se han observado dos procesos que, ininterrumpidamente, se han ido desarrollado hasta la riada de septiembre de 2019. Por un lado, el cauce blanco y completamente desprovisto de vegetación que se observa en los tres primeros fotogramas (1929-1930, 1945 y 1956) ha experimentado una colonización vegetal progresiva que, si bien ya es perceptible entre 1978 y 1993 , es notoria en los fotogramas de 2002 a 2017, hasta llegar a su máximo en las imágenes de 2018 y 2019 (figura 7B); mientras que, en las imágenes de 2020, posteriores a la riada de septiembre de 2019, solo se alcanza a reconocer, en el mejor de los casos, las cepas y los tocones de algunos de los tarayes que tapizaban el lecho, puesto que el resto de la vegetación riparia, de carácter herbáceo, ha sido completamente devastada (figura 7C).

El segundo proceso observado se vincula a los cambios de usos del suelo que, como ya se ha indicado, tuvieron su inicio con la llegada de recursos hídricos alóctonos (trasvase Tajo-Segura) y la transformación a regadío de todo este secano mejorado con las aguas de avenida del Campo de Benferri. Como ya se avanzó en otra ocasión (Marco et al., 2020), la principal consecuencia de esa profunda transformación paisajística y territorial ha sido el estrechamiento del cauce principal de la rambla; circunstancia en la que también han sido decisivos otros dos hechos: el desmantelamiento del sistema de riego con aguas de avenida y el desvío de la rambla hacia el embalse de Santomera. En efecto, el segundo debió materializarse hacia 1968 y se percibió como la principal causa de que las avenidas e inundaciones generalizadas en la cuenca del Segura de 1972 apenas tuvieran incidencia en la rambla de Abanilla-Benferri (de Gea et al.). De hecho, tal como se refleja en la tabla, las frecuentes riadas entre 1946 y 1967 dan paso a largos periodos de aparente inactividad, pues los eventos posteriores son los de 1987 y 2019. Muy probablemente, la conjunción de todas estas circunstancias -llegada de caudales alóctonos, desmantelamiento del sistema tradicional de riego con aguas de avenida y construcción de la presa y canal de derivación hacia el embalse de Santomera- generó una inercia y falsa percepción de seguridad ante el riesgo de avenidas de la rambla, que, entre otras, propició, mediante la roturación, el trazado y la mejora de la red viaria un progresivo estrangulamiento del cauce principal. Esta cuestión, estudiada en numerosos cauces mediterráneos (Conesa et al., 2012; Segura-Beltran \& Sanchis-Ibor, 2013; Segura-Beltran, 2017), se aborda ahora comparando los datos correspondientes a 1956, 2019 y 2020 en el área de estudio (entre el límite de la Región de Murcia y su derrame en El Ramblizo, Orihuela). Entre los dos primeros se produce una reducción del 38,29 \%, pues se ha pasado 
de $592.596 \mathrm{~m}^{2}$ a $365.675 \mathrm{~m}^{2}$; mientras que, a pesar de la recuperación derivada del episodio de 2020 en un $31,71 \%$ respecto de 2019 , los $481.636 \mathrm{~m}^{2}$ ocupados por el cauce significan una reducción del $18,72 \%$ respecto de 1956 .

\section{Discusión Y CONCLUSIONES}

Desde el comienzo se ha destacado el carácter multisecular, casi se podría decir que milenario, del funcionamiento ecoantrópico de la rambla. Muchos son los elementos presentados que avalan la idea de un sistema fluvial intensamente humanizado en el que, sin duda, ha coevolucionado la actividad hidrogeomorfológica, tanto en la faceta erosiva como en la sedimentaria, con la propia actividad antropogénica. Se trata de una interacción en la que los grupos humanos aprovechan los flujos de materia y energía del sistema hidrogeomorfológico para obtener los objetivos perseguidos (energía cinética ligada a la circulación de las aguas que, dirigida por los complejos de derivación, transporta no solo el agua, sino también la carga sólida) y que, en última instancia, pretenden aumentar el rendimiento y la productividad, mejorando así la capacidad de toda la superficie afectada por el sistema. Estos grupos, a través de su trabajo, también realizan un aporte energético, que, en la mayoría de los casos, se consume en contrarrestar los excesos que puedan dañar la infraestructura antropogénica del sistema.

Con esta lógica, ipara qué dejar fluir la rambla directamente hasta la vega del Segura, cuando existe un amplio y vasto territorio, denominado genéricamente "campo" - de Benferri, de Cox o de Redovánde tierras de secano en las que un riego podría asegurar las cosechas o aumentar la producción? Muy probablemente, esta cuestión y su respuesta más obvia están en el origen de las dificultades de interpretación que supone la firme convicción, basada en la percepción multisecular, de que el curso natural de la rambla aguas abajo de Benferri estaría representado por la denominada rambla de Redován. Sin descartar la posibilidad de que el sistema fluvial, antes de cualquier intervención antropogénica, pudiese tener varios derrames -fundamentalmente tres, como ya se ha dicho-, la respuesta a otra cuestión básica puede poner luz en este asunto o, al menos contribuir a ello. Si no existiese o elimináramos el Paredón, ¿cuál sería la situación o realidad alternativa? Pues parece evidente que la escorrentía se dirigiría en sentido sur, salvando el desnivel existente de prácticamente $10 \mathrm{~m}$; la corriente erosionaría los sedimentos acumulados a causa del Paredón y acabaría por exhumar el apuntamiento de rocas carbonatada del Triásico Superior en las que se apoya el estribo oeste de El Paredón, es decir, las que, con toda probabilidad, dieron nombre a la "Buelta de las Peñetas" del mapa del ACO. Constituyeron el anclaje idóneo para construir una primitiva "mota", que podría tener precedentes islámicos, que se menciona en el s. XIII (de Gea et al., 2012) y que, sin duda, fue objeto de reparaciones y ampliaciones constantes, especialmente a lo largo del s. XviII.

Se comprende así que, de forma paralela a su crecimiento, aumentase también el espesor de la acumulación de sedimentos inducida y, por consiguiente, el desnivel al que se encuentra el cauce en el que principia la rambla de Redován, paradójicamente colgado respecto de la base del Paredón. Se interpreta este punto como el inicio de una amplia zona de acreción que se digita a partir de la difluencia de las ramblas de Redován y de Cox, aunque también son importantes los derrames del complejo de boqueras 
del "Azud de Ortanova". Varios son los indicadores de esta acreción continuada en tiempos históricos, que vienen a corroborar la interpretación expuesta, completando las aproximaciones iniciales a esta cuestión (Marco et al., 2020):

- De la acreción de la parte distal por el sur, es decir, la correspondiente a la rambla de Redován, se tienen noticias desde 1490, cuando se indica que Redován "no era más de una grande alquería, y debía ser harta mejor tierra y más huerta de lo que es hoy, porque la acequia de Escorratel iba por mucho más arriba; pero con las avenidas de la rambla crece y se alza la tierra y decrece la huerta faltándole el agua" (Bellot, 2001: 180-181).

- En los dos planos del s. xvir se indica un elemento muy llamativo en sus leyendas: "Puente que està baxo tierra, y tiene de luz 19 palmos" (ACO) y "Puente que se ha descubierto bajo tierra, en termino de Redovan, que tiene de luz dies y nueve palmos y 24 piedras el Arco" (AHO). Se trata, aproximadamente, donde se situaría el ápice del abanico construido por la boquera-rambla de Redován.

- También la acequia-rambla de Cox y su prolongación en la Rambleta configuraron una zona de acreción que se advierte, además de por la circunstancia de circular por encima de los terrenos aledaños, por el trazado de las curvas de nivel, claramente convexas, observadas desde el ápice u oeste.

Se trata de las consecuencias más evidentes de un sistema que, durante siglos -tal vez algún milenio- se organizó para reducir las puntas de crecida, laminar los caudales y facilitar el avenamiento. Un sistema de ordenación hidrogeomorfológica que continuó su ampliación, al menos, durante los ss. XVIII y xix y que generó una compleja red de boqueras que, solo en el tramo analizado, beneficiaría una superficie superior a las 2.820 ha, según cálculos preliminares. Las dimensiones de esta red hidráulica suponían la detracción de ingentes caudales de la rambla: por ejemplo, teniendo en cuenta una altura de $30 \mathrm{~cm}$ en los caballones de los bancales, el sistema podría ser capaz de asumir hasta $8,46 \mathrm{hm}^{3}$. Una cifra aproximativa pero que da buena cuenta de la importancia del sistema y de las consecuencias de su desarticulación. En la riada catastrófica de 1947, que anegó Benferri y se llevó parte del cementerio situado junto al Paredón, se estima que la rambla evacuó 6 hm³ (Melgarejo, 1995); mientras que, en la de diciembre de 1965, el Segura evacuó por Guardamar $55 \mathrm{hm}^{3}$ a lo largo de varios días, con gran protagonismo de la rambla de Abanilla-Benferri (Rosselló, 1989). En estos episodios, de los que existen registros de caudal aproximado, el sistema de riego con aguas de avenida se encontraba en funcionamiento y debió de laminar ingentes cantidades de agua que, de otra manera, se hubieran sumado a las consecuencias desastrosas. Aunque se desconocen los datos de la riada de septiembre de 2019, algunos cálculos elevan los caudales de la rambla hasta los 74,02 hm³ (Benadero et al., 2020), lo que apunta a una clara sobreestimación. Pero parece lógico concluir que el abandono del sistema ha incrementado claramente la peligrosidad de las avenidas de la rambla, convertida actualmente en un foco de discusión técnica en el marco de la revisión del Plan de Gestión del Riesgo de Inundación en la demarcación hidrográfica del Segura, en su segundo ciclo de planificación 2022-2027 (CHS, 2021). Enlazar los avances en el conocimiento del funcionamiento del sistema histórico con las propuestas de futuro que pretenden reducir la peligrosidad de la rambla resulta un acicate para continuar su estudio. 


\section{RefERENCIAs}

Alberola, A. (2014). Los cambios climáticos. La Pequeña Edad del Hielo en España. Madrid: Cátedra.

Bellot, P. (2001). Anales de Orihuela: (siglos XIV-XVI). Alicante: I.A.C. Juan Gil-Albert / Real Academia Alfonso X el Sabio. 2 vols. Edición a cargo de J. Torres Fontes.

Benadero, J. V., Muguruza, P. I., \& Marin J. (2020). Estado de riesgo de la Vega Baja del río Segura frente a inundaciones. Necesidad de realizar un plan de infraestructuras hidráulicas. En López, I. \& Melgarejo, J. (eds.). Riesgo de inundación en España: análisis y soluciones para la generación de territorios resilientes (pp. 591-610). Alicante: Universidad de Alicante.

Bernabé, D. (1999). Insalubridad y bonificaciones de almarjales en el Bajo Segura antes de las Pías Fundaciones de Belluga. Revista de Historia Moderna, 17, 45-72.

Canales, G. \& López, A. (2015). Riesgos naturales en la huerta de Orihuela. En Ferrández, T. \& Diz, E. (coords.). Historia Natural de la Huerta de Orihuela (pp. 251-282). Orihuela: Ayuntamiento de Orihuela.

Cavanilles, A. J. (1795-1797). Observaciones sobre la historia natural, geografia, agricultura, poblacion y frutos del Reyno de Valencia. 2 vols. Madrid: Imprenta Real.

Comisión Nacional de Protección Civil (CNPC) (1983). Estudio de inundaciones históricas. Mapa de riesgos potenciales. Cuenca del Segura. 2 vols. https://www.chsegura.es/export/sites/chs/.galleries/ descargas_libros/Estudio_de_Inundaciones_Historicas_Mapas_de_Riesgos_Potenciales_Cuenca_ del_Segura.pdf

Conesa, C., Pérez, P., García, R., \& Martínez, A. (2012). Cambios históricos recientes de cauces y llanuras aluviales inducidos por la acción del hombre. Nimbus, 29, 159-176.

Confederación Hidrográfica del Segura (CHS). Cronología de riadas en la cuenca del Segura. https://www. chsegura.es/es/confederacion/unpocodehistoria/cronologia-de-riadas-en-la-cuenca-del-Segura/

CHS (2015). Plan de Gestión del Riesgo de Inundación de la demarcación hidrográfica del Segura. Murcia: Confederación Hidrográfica del Segura. Murcia: Confederación Hidrográfica del Segura. https:// www.chsegura.es/export/sites/chs/descargas/planificacionydma/planriesgoinundaciones/docsdescarga/01_PGRI_MEMORIA.pdf

CHS (2021). Revisión y actualización del Plan de Gestión del Riesgo de Inundación de la demarcación hidrográfica del Segura ( $2^{\circ}$ ciclo). Murcia: Confederación Hidrográfica del Segura. https://www.chsegura. es/export/sites/chs/descargas/planificacionydma/planriesgoinundaciones/docsdescarga/ESO70_ PGRI_2c_MemoriaCP.pdf

de Gea, M., Moñino, R., Marín, P., \& Marco, E. (2012). Los regadíos medievales y su evolución histórica en el Bajo Segura. Poblamiento, poder social y comunidades campesinas. Cuadernos de Historia y Patrimonio Cultural del Bajo Segura (4-5). Orihuela: Fundación de la Comunidad Valenciana "Patronato Histórico-Artístico de la ciudad de Orihuela".

Faus, A. (1995). Mapistes. Cartografia i agrimensura a la València del segle XVIII. València: Generalitat Valenciana. 
FEMP (2019). Sexto informe sobre políticas locales de lucha contra el cambio climático. Informe adicional: Soluciones Basadas en la Naturaleza. Infraestructuras Verdes de especial interés para las entidades locales. Madrid: Federación Española de Municipios y Provincias. https://sextoinforme.redciudadesclima.es/sites/default/files/2020-10/Sexto_Informe_sobre_Politicas_Locales_de_lucha_contra_el_ Cambio_Climatico_0.pdf

Gil, A. \& Canales, G. (1988). Residuos de propiedad señorial en España. Alicante: I.A.C. Juan Gil-Albert.

Giménez-Font, P. (2006). Contexto geomorfológico y asentamiento humano: abanicos aluviales y corrientes de derrubios en la sierra de Callosa (Bajo Segura, Alicante). Geografía física y medio ambiente: guía de campo de las XXI Jornadas de Geografía Física (pp. 95-120). Alicante: AGE-Instituto Interuniversitario de Geografía.

Hernández, M. \& Giménez, P. (2011). La citricultura: un paisaje dual, entre los regadíos tradicionales de los valles aluviales y los nuevos regadíos. Los paisajes agrarios de España. Caracterización, evolución y tipificación (pp. 336-349). Madrid: Ministerio de Medio Ambiente, Rural y Marino.

Hernández, M. \& Morales, A. (2013). Los aprovechamientos tradicionales de las aguas de turbias en los piedemontes del sureste de la Península Ibérica: estado actual en tierras alicantinas. BAGE, 63, 105-123.

Juárez, C., Ponce, G. \& Canales, G. (1989). Inundaciones en el Bajo Segura. Cronología de una lucha intermitente frente a una amenaza constante (1946-1987). En Gil, A. \& Morales, A. Avenidas fluviales e inundaciones en la cuenca del Mediterráneo (pp. 309-329). Alicante: Instituto Universitario de Geografía, Universidad de Alicante.

Marco, J. A. (2016). Técnicas tradicionales de información geográfica (TTIG) en el análisis de las transformaciones recientes del riu Millars (Castelló, España). En Vera, F., Olcina, J., \& Hernández, M. (coords.). Paisaje, cultura territorial y vivencia de la geografía: Libro homenaje al profesor Alfredo Morales Gil (pp. 273-288). Alicante: Instituto Interuniversitario de Geografía, Universidad de Alicante.

Marco, J. A. \& Box, M. (2019). El conocimiento tradicional relativo al aprovechamiento de las aguas de avenida: l'Alcavó i la Revolta. Canelobre, 70, 196-205.

Marco, J. A., Giménez, P., Padilla, A., Garcia, E., \& Prieto, A. (2020). La rambla de Abanilla-Benferri como paradigma para el estudio del conocimiento tradicional relativo al aprovechamiento de las aguas de avenida. En López, I. \& Melgarejo, J. (eds.). Riesgo de inundación en España: análisis y soluciones para la generación de territorios resilientes (pp. 881-896). Alicante: Universidad de Alicante.

Marín, P. (1997). Historia de Cox según Montesinos. Callosa de Segura: Imp. Gráficas San Roque.

Melgarejo, J. (1995). La intervención del Estado en la cuenca del Segura (1926-1986). Alicante: Institut de Cultura Juan Gil-Albert, Generalitat Valenciana.

Mondéjar, J. M. (2009). El riego de boqueras: una técnica hidráulica para la gestión ambiental en territorios semiáridos y lucha contra la desertificación. Tesis doctoral (inédita). Alicante: Instituto Interuniversitario de Geografía, Universidad de Alicante.

Morales, A. (1969). El riego con aguas de avenida en las laderas subáridas. Papeles del Departamento de Geografía, 1, 167-187. 
Morales, A. \& Box, M. (1986). El aprovechamiento del agua y los suelos en un dominio semiárido: la cuenca del barranco Blanco, Agost (Alicante). Investigaciones Geográficas, 4, 7-24.

Morales, A., Box, M., \& Marco, J. A. (1989). El aprovechamiento de las aguas de avenida: derecho consuetudinario y disposiciones legales. En Gil, A. \& Morales, A. (eds.). Avenidas fluviales e inundaciones en la cuenca del Mediterráneo (pp. 553-563). Alicante: Instituto Universitario de Geografía, Universidad de Alicante.

Nipho, J. M. (1770). Correo general de España, y noticias importantes de agricultura, artes, manufacturas, comercio, industria y ciencias. Madrid: Ed. facsímil del Ministerio de Agricultura, Pesca y Alimentación, 1988. Tomo 1.

Ojeda, J. (2011). Evolución de las tandas de riego en Orihuela. Cuadernos de Geografía, 89, 23-48.

Oliva, A. \& Olcina, J. (2021). La importancia de la cartografía histórica en la elaboración de mapas de peligrosidad de inundación en el contexto del cambio climático: Propuestas para la rambla de Abanilla (Alicante). Estudios Geográficos, 82(290), e069. https://doi.org/10.3989/ estgeogr.202081.081

Ortuño, A., Folgueral, S., \& Amorós, F. (2020). El Foro Fuerza Vega Baja: necesidades y posibilidades de financiación. En López, I. \& Melgarejo, J. (eds.). Riesgo de inundación en España: análisis y soluciones para la generación de territorios resilientes (pp. 1107-1128). Alicante: Universidad de Alicante.

Rosselló, V. M. (1989). Los llanos de inundación. En Gil, A. \& Morales, A. (dir.). Avenidas fluviales e inundaciones en la cuenca del Mediterráneo (pp. 243-283). Alicante: Instituto Universitario de Geografía, Universidad de Alicante.

Segura-Beltrán, F. \& Sanchis-Ibor, C. (2013). Assessment of channel changes in a Mediterranean ephemeral stream since the early twentieth century. The Rambla de Cervera, eastern Spain. Geomorphology, 201, 199-214.

Segura-Beltrán, F. (2017). Canvis ambientals i antròpics recents en els sistemes fluvials mediterranis: crònica d'una destrucció anunciada. Barcelona: Institut d'Estudis Catalans.

Cómo citar este artículo:

Marco Molina, J. A., Giménez Font, P., \& Prieto Cerdán, A. (2021). Aprovechamiento tradicional de las aguas de avenida y transformaciones de los sistemas fluviales del sureste de la Península Ibérica: la Rambla de AbanillaBenferri. Cuadernos de Geografía, 107, 149-174.

https://doi.org/10.7203/CGUV.107.21333

\section{(C) (1) $\Theta \Theta$}

Este obra está bajo una licencia de Creative Commons Reconocimiento-NoComercial-SinObraDerivada 4.0 Internacional. 